
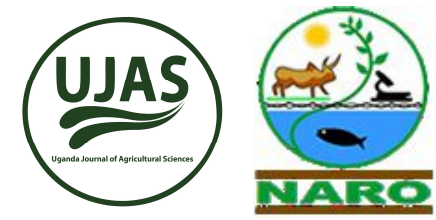

\title{
Host Range of Cotton Flea Beetle (Podagrica puncticollis) in a Hot Dry Tropical Environment of Ethiopia
}

\author{
Agegnehu E. ${ }^{1, *}$, Mulatu B. ${ }^{2}$, Damte T. ${ }^{3}$, Wakgari M. ${ }^{1}$ \\ ${ }^{1}$ School of Plant Sciences, Haramaya University, Dire Dawa, Ethiopia. \\ ${ }^{2}$ Food and Agriculture Organization Ethiopia. \\ ${ }^{2}$ Ethiopian Institute of Agricultural Research, Debre Zeit Centre, Debre Zeit, Ethiopia. \\ *Corresponding author. @ agegnehueshetu70@gmail.com
}

\begin{abstract}
Cotton flea beetle, Podagrica puncticollis is the most destructive insect pest of cotton in north-western part of Ethiopia. This study was conducted to identify and determine the host range of cotton flea beetle in Metema area. The field survey was undertaken from June 27, 2015 to January 9, 2016 in ten kebele administrations of the district. At least three fields were prospected after every 15 days, in each kebele for host plants as well as to determine population density and percent leaf damage by adult cotton flea beetle, at different growth stages of cotton plant. The composition of plant species with damaged symptom or infested by flea beetle was analysed using quantitative means and identified by comparing specimens with description of identification manuals. A total of 11 host plant species of cotton flea beetle were identified in the cotton growing areas of Metema throughout a season. Indigofera longibarbata (Fabaceae), Hibiscus articulatus, H. cannabinus, H. vitifolius, Abutilon figarianum, Sida alba and S. urens (Malvaceae), Bidens pilosa and B. setigera (Asteraceae), Corchorus olitorius and C. trilocularis (Tiliaceae) found to be common host plants of cotton flea beetle. Thus, among the host plants, $H$. vitifolius, $H$. cannabinus, $H$. articulatus, $C$. olitorius and $C$. trilocularis were the most suitable hosts for adult cotton flea beetle in respect of the number of adults per plant and percent foliage damage they sustained. These findings could aid in developing longterm management strategies for this important insect pest existing in a hot dry tropical environment of north-western Ethiopia.
\end{abstract}

Keywords: Podagrica puncticollis, Host range, Population, Leaf damage.

\section{Introduction}

There are four species of flea beetles on cotton (Gentry, 1965; Ermias et. al., 2009) and it is only P. Puncticollis which is the dominant species recorded on cotton in Ethiopia and the neighbouring countries as economic pest (IAR, 1972; Ermias et. al., 2009). Yield loss of 75.51\% was recorded in untreated cotton than cotton grown from Cruiser treated seeds and sprayed with Sevin 5 days after seedling emergence in Metema district, north-western Ethiopia (Abebe, 2015). 
Flea beetles feed on cotyledons and leaves of growing plants by removing the upper layers of leaf tissue thereby severely restricting photosynthesis and assimilation and resulting in stunted growth (Frohlich and Rodeward, 1969). La Croix (1961) and Ripper and George (1965) reported that early sown cotton is liable to heavier attack by flea beetles than later sown cotton. Moreover La Croix (1961) and Bukenya (2004) indicated that flea beetles are present in cotton field at all stages of growth and the attack at the seedling stage is more harmful than later infestation. Early damage to seedlings causes stand losses and produces plant stands with uneven height and maturity. Delayed maturity following flea beetle damage may expose the crop to adverse temperatures during flowering or to frost before the plants have matured (Throne, 2007).

Studies on the life history and bionomics of cotton flea beetles were made by Pollard (1955) and Schmutterer (1969). The female lays its small yellow eggs in the soil at the base of the host plants. The larvae hatch after 7-11 days and feed for a period of 11 to 28 days on the rootlets of volunteer crops and weeds and move to newly planted crops as they emerge. It is extremely difficult to locate them with the larvae doing none or no serious damage (Lloyd and Ripper, 1965). Pupation takes place in the soil (Hill, 1994). Adults emerge from the pupae after 10-17 days. A number of generations can appear during a season. Adults remain on the host plant after the rainfall as long as they can find suitable food. They always prefer young plants. When the cotton plants are harvested and dry, the beetles migrate into soil cracks or beneath plant debris where they spend the dry season. They become active in early onset of rainfall i.e. before the cracks are closed by rain and begin feeding on weeds or early planted crops (Delahaut, 2001). When such plants are found, the beetles settle on and consume larger quantities of food in proportion to their size (Schmutterer, 1969). Flea beetle life history varies with species, but most appear to pass the dry period in the adult stage, sheltering under plant debris in the field, field margins, and adjacent areas (Metcalf, 1993). They typically begin to become active during warm days in rainy season, but may spread out over several weeks. Many flea beetles are strong fliers and seek out emerging host plants, which they locate by chemical cues that the plants produce (Kenneth, 1995).

Climatic conditions and time of sowing of cotton are the most important factors affecting the prevalence of the flea beetle (Lloyd and Ripper, 1965). Setting of rainfall starting lately during main cotton growing season lead to severe attack of the beetle on cotton seedlings where there is less food on weeds for the flea beetle when they emerge from aestivation.

The host range of an herbivore species is considered to comprise those plant species that are accepted in the field (Schaffner, 2001); while, host plant preference is defined as the chance that an insect will accept a certain host if encountered (Singer et al., 1992). Schoonhooven et al. (1998) stated that an herbivorous insect's host plant range is dynamic, and host plant preference of phytophagous insects can be variable between and within insect populations due to factors related to both host plants and insects, including geographical location, seasonality, developmental stage, sex, and temperature. Most insects prefer host plants that will optimize their survival and reproduction (Dodge et al., 1990).

Insects differ in their decisions to accept a food source, initiate feeding or oviposit, which is influenced by a variety of internal and external factors such as chemicals emitted from the host plant and state of the insect (Kennedy, 1978; Schultz, 1988; Bernays, 1995). Most attractive plant substances are secondary metabolites (allelochemicals), which are assumed to have originated as by-products of plant primary metabolism (Hartmann, 1996) and are both volatile and non-volatile. Such substances may mediate plant-insect interactions as attractants, repellents, stimulants, or deterrents to feeding/oviposition (Starr et al., 1991). 
Alternative host plants can play a significant role in the biology of a number of crop insect pests (Jones et al., 1992). For instance, the main plants that host the cotton flea beetle, which is a seedling pest of cotton, belong to the family Malvaceae, including Hibiscus esculentus, $H$. cannabinus, $H$. sabdariffa and $H$. dongolensis contributes to the survival of adult beetles during the dry season. Moreover, other wild plants such as Abutilon glaucum, A. angulatum, A. figarianum and Sida sp. (Schmutterer, 1969), Adansonia digitata (Tebeldi) and Corchorus olitorius (Melochia) hosts of cotton flea beetle hosts that aggravate the pest problem in different cotton growing areas (Abdin, 1962).

Plants in the family Malvaceae are known as potential hosts of various insect pests in the field. Taxonomic similarity between the weed and crop plant becomes an important element in predicting damage to crops by weed-feeding insects. Insects with a narrow host range (specialists) are likely to be pre-adapted to accept crops in the same family as the weeds on which they feed (Capinera, 2002). Hill (1987) listed Dysdercus spp., Nezara viridula, Earias spp. and Podagrica spp. as pests common to a number of Malvaceae plants.

Flea beetles are members of the sub-family Alticinae in the leaf beetle family Chrysomelidae, one of the most destructive of insect families. The Alticinae, the largest chrysomelid subfamily, has 6,000 species worldwide, most of which are phytophagous (Soroka, 2008). The Alticinae are generally not very specific in their choice, more than 100 plant families, from Gymnospermae to Monocotyledoneae or Dicotyledoneae. They show very often biological races, morphologically similar but feeding in the same area on very different host-plants. Seasonal races have also been quoted among the Alticinae (White, 1973).

The wide range of feeding and/or reproductive hosts, especially continuous production of preferred host crops and presence of abundant alternative wild host species facilitates insect pests' perpetuation. Adewole (2010) stated that there is a need to conduct research on the host preference of Podagrica spp. in the family Malvaceae. Moreover, considering that most flea beetles are of temperate origin, studying the survival strategy of flea beetles in a tropical environment on the different host plants they inhabit is essential. Such work is very limited for flea beetles under Ethiopian conditions including cotton flea beetles.

In the study area to date farmers control cotton flea beetles using insecticide applied in spray form or earlier as seed dresser. Nevertheless, the economic significance of the insect has not been reduced due to such interventions and cotton growers continue to suffer significantly from the pest attack. To date, the information locally generated on cotton flea beetle biology, ecology and management are very scanty thus require detailed studies on cotton flea beetle, biology, ecology and management. Generating such information is important to design effective and sustainable management strategy against cotton flea beetle in cotton in Ethiopia.

In Metema district where cotton is an important commodity, cotton flea beetle host range has not been fully determined. It is a dry land that receives rainfall only between June and September. However, the source of infestation at the start of the cotton growing season has not been described. Knowing the host range of cotton flea beetle in Metema helps the development of appropriate management methods. Therefore, this study investigated the host range of the beetle in the cotton producing areas of Metema district, north-western Ethiopia.

\section{Materials and Methods}

The study was undertaken from June 22, 2015 to January 9, 2016 in ten kebele administrations within Metema district. The kebeles were Agam Wuha, Das, Genda Wuha, Gubay, Kokit, 
Kumer-Aftit, Meka, Mender 7, Metema Yohannes, and Shenfa. Primary data were gathered through observation in the field. The survey was carried out by visiting fields sown to cotton, sorghum, and sesame grown in the preceding crop season as well as in the nearby forest covers up to the end of main cotton growing season.

During the main growing season, besides cotton, several cultivated and wild plant species, which were grown in crop fields, non-cultivated areas, crop field boarders, road sides and riverine forests were examined to determine whether they were hosting cotton flea beetle or not. In each selected cotton field, each four sides of the field were prospected and the vicinity fallow was also visited up to 50 meters from the cotton field. The observations were done along a diagonal of a cotton field. At least three fields were visited in every fifteen days in each representative kebele. During the survey time, species of plants with damage symptoms or infested by adult cotton flea beetles and their growth habit as well as leaf morphology were determined. Growth stages of cotton plants nearby the surveyed fields were recorded.

The plant species with damage symptom or infested by cotton flea beetle were identified by comparing specimens with description of Haile et al. (2012), Ermias Dagne Company called NDA (Natural Database for Africa, file version: 2.0.) and Website of Ariti Herbal (NDA, 2011). Local names of known host plants of cotton flea beetle were identified by contacting local botanists or well experienced cotton farmers and cross checking with concerned experts of the districts.

Cotton flea beetle individuals were counted on each sample plant. For the dominant and commonly occurring plant species 10 to 20 plants were randomly selected per survey date, while for scattered and rare species, all the plants present at a given site were considered as sample units per sample site. Therefore, purposive sampling technique was used to sample the alternative host plant species of cotton flea beetle.

Calculations of percent leaf damage caused by adult cotton flea beetles were done on a total of 20 leaves from each individual plant species. Under heavy infestations the sheer number of feeding pits can give the fragile young leaves a shot hole appearance. Hence the rate of damage of leaves was estimated by a visual rating method based on the amount of leaf area removed. The percent leaf damage caused by adult cotton flea beetle was determined based on the method described by Anonymous (2011) as:

$$
\text { Percentage damage }=\frac{\text { No. of damaged leaves }}{\text { Total Number of leaves assessed }} \times 100
$$

The level of damage was based on the amount of leaf area removed and was accordingly categorized as:

$\begin{array}{lll}\text { Light } & : & \text { (Less than } 10 \% \text { defoliation) } \\ \text { Moderate } & : & \text { (Between } 10 \text { to } 30 \% \text { ) } \\ \text { Severe } & : & \text { (Greater than } 30 \% \text { ) }\end{array}$

Host plant species composition was evaluated both at the vegetative (30-40 days after emergence) and near flowering (60-70 days after sowing) stages of cotton in Metema cottongrowing areas. Alternative host plant species composition was analysed by abundance (A), dominance (D), and frequency $(\mathrm{F})$, based on the formula $(1-3)$ described by Taye and Yohannes (1998) as follows:

$$
F=\frac{X}{N} \times 100
$$

Where, $\mathrm{F}=$ frequency; $\mathrm{X}=$ number of occurrences of a weed species; $\mathrm{N}=$ sample number. 
Abundance of weed spp. was calculated using the formula:

$$
A=\frac{\sum W}{N}
$$

Where, $\mathrm{A}=$ abundance, $\mathrm{W}=$ number of individuals of a weed species, $\mathrm{N}=$ sample number.

Dominance of weed spp. was calculated using the formula:

$$
D=\frac{A}{\sum A} \times 100
$$

Where, $\mathrm{D}=$ dominance, $\Sigma \mathrm{A}=$ total abundance of all species.

The data were analysed through descriptive statistics to generate summaries and tables. Single sample t-test was used to check for statistical significance of differences between mean densities of adult cotton flea beetle and extent of leaf damage due to this pest (using SPSS, version 16). Insect counts were transformed using the square root $(x+1)$ prior to data analysis.

\section{Results and Discussion}

\section{Composition of alternative host species of cotton flea beetle}

A total of 11 alternative host plant species of adult cotton flea beetle were identified in the cotton growing areas of Metema throughout the cropping season (Table 1). These were distributed in the family Malvaceae, Asteraceae, Tiliaceae and Fabaceae, which accounted for $54.55,18.18,18.18$, and $9.09 \%$ of the species, respectively. Malvaceae was the most diverse group (cf. Pulschen, 1990). Hill (1987) reported that the family Malvaceae is known as potential hosts of various insect pests on the field. Moreover, reported that in tropical and subtropical regions representative of genus Podagrica spp. regularly threaten plant species from family Malvaceae (Cmoluch, 1988; Adewole, 2010). ZongZhao and SiQin (2005) reported host specialization in up to $85 \%$ of Alticinae, despite their broad host range. On the other hand, Mayoori and Mikunthan (2009) reported that flea beetles have a wider host range extended to the families Brassicaceae, Amaranthaceae, Asteraceae, Capparidaceae, Euphorbiaceae, Solanaceae, Chenopodiaceae, Convulvulaceae and Fabaceae.

\begin{tabular}{|c|c|c|c|}
\hline Botanical name & Family & Characteristics & Source of identification \\
\hline Bidens pilosa $\mathrm{L}$. & Asteraceae & $\mathrm{A}, \mathrm{H}, \mathrm{E}$ & Mesfin,T., 2004 \\
\hline Bidens setigera $\mathrm{Sch}$. & Asteraceae & $\mathrm{A}, \mathrm{H}, \mathrm{E}$ & Mesfin, T., 2004 \\
\hline Indigofera longibarbata Engl. & Fabaceae & $\mathrm{A}, \mathrm{P}, \mathrm{H}$ & Hedberg \& Edwards, 1989 \\
\hline Abutilon figarianum Webb & Malvaceae & $\mathrm{A}, \mathrm{P}, \mathrm{H}$ & Vollesen, K., 1995 \\
\hline $\begin{array}{l}\text { Hibiscus articulatus Hochst. Ex A. } \\
\text { Rich. }\end{array}$ & Malvaceae & $\mathrm{A}, \mathrm{H}$ & Vollesen, K., 1995 \\
\hline Hibiscus cannabinus L. & Malvaceae & $\mathrm{A}, \mathrm{H}$ & Mesfin, T., 2004 \\
\hline Hibiscus vitifolius L. & Malvaceae & $\mathrm{A}, \mathrm{H}$ & Vollesen, K., 1995 \\
\hline Sida alba L. & Malvaceae & $\mathrm{A}, \mathrm{P}, \mathrm{H}, \mathrm{E}$ & Vollesen, K., 1995 \\
\hline Sida urens L. & Malvaceae & $\mathrm{A}, \mathrm{P}, \mathrm{H}, \mathrm{E}$ & Vollesen, K., 1995 \\
\hline Corchorus olitorius L. & Tiliaceae & $\mathrm{A}, \mathrm{H}, \mathrm{E}$ & Edwards, et al.1995 \\
\hline Corchorus trilocularis L. & Tiliaceae & $\mathrm{A}, \mathrm{H}, \mathrm{E}$ & Vollesen, K., 1995 \\
\hline
\end{tabular}

Table 1. Alternative hosts of adult cotton flea beetle identified in Metema district

$\mathrm{A}=$ Annual, $\mathrm{P}=$ Perennial, $\mathrm{H}=\mathrm{Herb}, \mathrm{E}=$ Erect 
Most of the alternative host plant species (99\%) identified in Metema area were erect annual or perennial herbs (Table 1). Abutilon figarianum, Bidens pilosa, B. setigera, Hibiscus articulatus, $H$. cannabinus, $H$. vitifolius and Indigofera longibarbata hosted the beetle before the cotton crop emerged in the surveyed fields. On the remaining host plant species cotton flea beetles were found a week after emergence of cotton plant.

\section{Frequency and Dominance of Cotton Flea Beetle alternative Host Species}

The frequency and infestation levels of individual alternative host species of cotton flea beetle ranged from 6 to $71 \%$ and 1 to $23 \%$, respectively at vegetative stage of the cotton crop (Table 2). The most dominant alternative host species of cotton flea beetle was Hibiscus vitifolius, contributing up to $23 \%$ of the infestation in the surveyed fields. Generally, the major alternative host species of cotton flea beetle at seedling stage were Abutilon figarianum, Bidens pilosa, B. setigera, Hibiscus articulatus, $H$. cannabinus, $H$. vitifolius and Indigofera longibarbata (Table 2).

Table 2. Alternative hosts of cotton flea beetle at the vegetative stage of the cotton crop

\begin{tabular}{llll}
\hline Botanical name & Frequency & Abundance & Dominance \\
\hline Abutilon figarianum & 46.66 & 2.133 & 15.60 \\
Bidens pilosa & 16.66 & 0.433 & 3.16 \\
Bidens setigera & 10.00 & 0.233 & 1.70 \\
Corchorus olitorius & 12.50 & 0.250 & 1.82 \\
Corchorus trilocularis & 14.28 & 0.375 & 2.74 \\
Hibiscus articulatus & 42.85 & 1.857 & 13.58 \\
Hibiscus cannabinus & 57.14 & 2.571 & 18.80 \\
Hibiscus vitifolius & 71.42 & 3.142 & 22.98 \\
Indigofera longibarbata & 53.33 & 2.433 & 17.79 \\
Sida alba & 5.88 & 0.117 & 0.85 \\
Sida urens & 6.25 & 0.125 & 0.91 \\
\hline
\end{tabular}

On the other hand, the frequency and infestation levels of individual alternative host species of cotton flea beetle near flowering stage of the crop ranged from 6 to $78 \%$ and 1 to $25 \%$, respectively. The main alternative host species of cotton flea beetle at early flower initiation stage of cotton were Corchorus olitorius, C. trilocularis, Sida alba and S. urens (Table 3).

Table 3. Alternative hosts of cotton flea beetle at the beginning flowering stage of cotton crop

\begin{tabular}{llll}
\hline Botanical name & Frequency & Abundance & Dominance \\
\hline Abutilon figarianum & 45.16 & 1.774 & 14.10 \\
Bidens pilosa & 9.67 & 0.193 & 1.53 \\
Bidens setigera & 6.45 & 0.129 & 1.02 \\
Corchorus olitorius & 66.66 & 2.666 & 21.19 \\
Corchorus trilocularis & 77.77 & 3.111 & 24.72 \\
Hibiscus articulatus & 12.50 & 0.250 & 1.98 \\
Hibiscus cannabinus & 22.22 & 0.555 & 4.41 \\
Hibiscus vitifolius & 27.27 & 0.636 & 5.05 \\
Indigofera longibarbata & 51.61 & 2.032 & 16.15 \\
Sida alba & 23.52 & 0.588 & 4.67 \\
Sida urens & 29.41 & 0.647 & 5.14 \\
\hline
\end{tabular}


Among the different alternative host species of cotton flea beetle at the beginning of flowering stage of cotton, the species Corchorus trilocularis, contributed up to $25 \%$ of the infestation in the surveyed fields However, Corchorus spp. were also the dominant host species which frequently flourished till harvesting of the crop. Esayas et al. (2012) reported that near harvest stage of the crop, Corchorus spp. was the most frequent and dominant weed species contributing to $36 \%$ of infestation of the cotton fields in Metema district. According to the present work, among the alternative host species, Corchorus species may serve as a host for adult cotton flea beetle from seedling stage up to harvesting of the crop. According to Furth (1979) several species of Phyllotreta in Israel have a succession of host plants, starting with an early germinating, longlived, widespread species or several species and then moving to a preferred host plant for most of the season, but afterwards often returning to less desirable or less preferred hosts late in the season.

\section{Cotton Flea Beetle Population Intensities on the Alternative Host Species}

In general there was significant difference in the number of adult cotton flea beetle recorded on the different alternative hosts and also between the sampling days for each species. In the first sampling date, the highest number of cotton flea beetle was recorded in Hibiscus vitifolius followed, in decreasing order, by H. cannabinus, $H$. articulatus, Abutilon figarianum, Bidens pilosa and B. setigera. On the other hand, few individuals of cotton flea beetles were found in Corchorus olitorius, Sida urens, Indigofera longibarbata, and Sida alba (Table 4).

Table 4. Cotton flea beetle on alternative host species over the growing season (Metema 2015)

\begin{tabular}{|c|c|c|c|c|c|c|c|c|}
\hline \multirow[t]{2}{*}{ Botanical name } & \multicolumn{6}{|c|}{$\begin{array}{l}\text { Adult cotton flea beetle (per plant) after cotton } \\
\text { emergence }\end{array}$} & \multirow[t]{2}{*}{ SEM } & \multirow[t]{2}{*}{$\begin{array}{l}\mathrm{P}- \\
\text { value }\end{array}$} \\
\hline & Initial & $20 D A E$ & $30 D A E$ & $40 D A E$ & $50 D A E$ & $60 D A E$ & & \\
\hline Abutilon figarianum & 4.33 & 4.00 & 3.33 & 3.00 & 2.00 & 1.00 & 0.51 & 0.002 \\
\hline Bidens pilosa & 4.00 & 3.66 & 3.00 & 2.50 & 1.33 & 0.80 & 0.51 & 0.004 \\
\hline Bidens setigera & 3.33 & 2.66 & 2.00 & 1.66 & 1.00 & 0.78 & 0.39 & 0.005 \\
\hline Corchorus olitorius & 2.50 & 2.33 & 2.00 & 6.00 & 5.33 & 4.00 & 0.68 & 0.003 \\
\hline $\begin{array}{l}\text { Corchorus } \\
\text { trilocularis }\end{array}$ & 2.00 & 2.00 & 1.50 & 5.50 & 4.66 & 3.50 & 0.66 & 0.005 \\
\hline Hibiscus articulatus & 4.66 & 4.33 & 4.00 & 3.50 & 1.66 & 1.05 & 0.6 & 0.003 \\
\hline Hibiscus cannabinus & 6.00 & 5.33 & 4.66 & 3.50 & 2.00 & 1.10 & 0.78 & 0.005 \\
\hline Hibiscus vitifolius & 7.66 & 6.00 & 5.00 & 4.33 & 3.00 & 1.38 & 0.9 & 0.004 \\
\hline $\begin{array}{l}\text { Indigofera } \\
\text { longibarbata }\end{array}$ & 1.66 & 1.50 & 1.33 & 1.00 & 1.00 & 0.49 & 0.17 & $<0.01$ \\
\hline Sida alba & 1.33 & 1.00 & 1.00 & 4.00 & 3.33 & 2.44 & 0.52 & 0.009 \\
\hline Sida urens & 2.00 & 1.33 & 1.00 & 4.60 & 4.00 & 2.82 & 0.59 & 0.007 \\
\hline SEM & 0.59 & 0.5 & 0.44 & 0.45 & 0.45 & 0.36 & & \\
\hline P-value & $<0.01$ & $<0.01$ & $<0.01$ & $<0.01$ & $<0.01$ & $<0.01$ & & \\
\hline
\end{tabular}

$\mathrm{SEM}=$ Standard error of the mean; DAE $=$ Days after Emergency

At 20 days after emergence (DAE), the highest number of adult cotton flea beetle per plant was recorded in Hibiscus vitifolius followed, in decreasing order, by $H$. cannabinus, H. articulatus, Abutilon figarianum and Bidens pilosa. While, least individuals of cotton flea beetles were found in 
Bidens setigera, Corchorus olitorius, C. trilocularis, Indigofera longibarbata, Sida urens and S. alba (Table 4). In contrast at $40 \mathrm{DAE}$ the highest number of cotton flea beetles per plant was present on Corchorus spp. followed by Sida spp. (Table 4).

\section{Leaf Damage by Cotton Flea Beetle on Alternative Host Species}

Percent leaf damage caused by cotton flea beetle was significantly different among the alternative host species. Thus, at the start of the assessment higher infestation was recorded on Hibiscus vitifolius, $H$. cannabinus, $H$. articulatus and Abutilon figarianum than on Indigofera longibarbata (Table 5). At 40 DAE, the leaves of Corchorus olitorius were heavily damaged by cotton flea beetles than remaining alternative hosts (Tables 5). This result is similar with the work of Adeyela and Thomas (2013) who reported that the most abundant insect pests associated with the jute (Corchorus olitorius L.) were Podagrica sp., Sylepta sp., Dsysdercus sp., and Zonocerus sp.

Thus, among the alternative host species, Hibiscus vitifolius, H. cannabinus, H. articulatus, Corchorus olitorius and C. trilocularis were the most suitable host for adult cotton flea beetle at different times of cotton growing season. On the other hand, Indigofera longibarbata and Bidens setigera were the least preferred alternative host species to adult cotton flea beetle.

Table 5. Percent leaf damage on alternative host species at the first assessment and various days after emergence of cotton crop (Metema 2015)

\begin{tabular}{lccccccccc}
\hline Botanical name & \multicolumn{4}{c}{ Percent damage per 20 leaves } & \multicolumn{5}{c}{ SEM P-value } \\
& Initial & 20 DAE & 30 DAE & 40 DAE & 50 DAE & 60 DAE & \\
\hline Abutilon figarianum & 35.00 & 31.25 & 28.00 & 23.75 & 18.00 & 12.00 & 3.49 & $<0.01$ \\
Bidens pilosa & 28.75 & 25.00 & 22.00 & 17.50 & 12.50 & 7.50 & 3.24 & 0.002 \\
Bidens setigera & 26.25 & 23.75 & 18.75 & 13.75 & 10.00 & 6.25 & 3.20 & 0.004 \\
Corchorus olitorius & 30.00 & 27.50 & 26.25 & 37.50 & 25.00 & 35.00 & 2.05 & $<0.01$ \\
Corchorus trilocularis & 28.70 & 26.25 & 25.00 & 36.25 & 23.75 & 32.50 & 1.96 & $<0.01$ \\
Hibiscus articulatus & 48.75 & 43.00 & 37.50 & 31.00 & 26.25 & 21.00 & 4.26 & $<0.01$ \\
Hibiscus cannabinus & 53.00 & 51.25 & 47.50 & 38.75 & 28.00 & 23.75 & 5.03 & $<0.01$ \\
Hibiscus vitifolius & 55.00 & 53.75 & 48.75 & 42.50 & 31.00 & 26.00 & 4.91 & $<0.01$ \\
Indigofera & 18.75 & 15.00 & 12.50 & 8.75 & 6.25 & 3.75 & 2.29 & 0.005 \\
longibarbata & & & & & & & \\
Sida alba & 23.75 & 20.00 & 17.50 & 29.00 & 17.00 & 28.75 & 2.19 & $<0.01$ \\
Sida urens & 25.00 & 21.25 & 21.00 & 31.25 & 20.00 & 30.00 & 1.98 & $<0.01$ \\
SEM & 3.77 & 3.89 & 3.60 & 3.31 & 2.37 & 2.40 & & \\
P-value & $<0.01$ & $<0.01$ & $<0.01$ & $<0.01$ & $<0.01$ & $<0.01$ & & \\
\hline SEM Sta & & &
\end{tabular}

$\mathrm{SEM}=$ Standard error of the mean; DAE = Days after Emergency.

Mayoori and Mikunthan (2009) reported that weeds belonging to family Poaceae were not preferred by the flea beetles and the current study did not find a grass species that hosts cotton flea beetle. Also no adult flea beetle was observed on sesame and sorghum crops throughout the study period.

During the survey time, cotton phenology dependent distribution of cotton flea beetle was observed along with host range study. The pest attack on cotton began one week after crop emergence in the second week of July, which coincided with the emergence of crop in the area. Difference in the number of adult cotton flea beetles was recorded at different growth stages of cotton plant in the growing season. Perusal of data revealed that the cotyledon stage recorded highest number of 5.12 adult cotton flea beetles per 50 leaves followed by first true leaf (4.74 
beetles per 50 leaves). The lowest number of 0.02 adult cotton flea beetle per 50 leaves was recorded at second picking followed by first picking (0.05), 60\% open boll (0.16), first open boll (0.23) and peak bloom (0.53) stages. On the other hand, the percent leaf damage caused by adult cotton flea beetle was observed on four early phenological stages of the crop and highest severity of leaf damage of 34.6 percent per 50 leaves was recorded during cotyledon stage followed by first true leaf $(31.7 \%)$ and first several true leaves $(27.33 \%)$ stages. Generally, the rate of population density of adult cotton flea beetle and associated damage were decreased with the increase of the age of the cotton plants.

Based on the findings of the present survey, Hibiscus spp. were therefore, the most susceptible alternative hosts to the cotton flea beetle as compared to other species and even with cotton crop. Consequently, Hibiscus spp. could be used as a trap crops for the effective control of cotton flea beetle.

\section{Conclusions}

Once the cotton flea beetle appeared in the fields before cotton crop establishment, the alternative host species especially Malvaceae weeds like Hibiscus spp. provided an early food supply for adults, thereby greatly fostering its survival and increasing the severity of its attacks on the seedling stage of emerging cotton seedlings. On the other hand, Corchorus spp. played a great role through supplying food for adult cotton flea beetles during the end of vegetative stages to near maturity stages of cotton. However both plant species were the most preferred alternative hosts for adult cotton flea beetle at different times of cotton growing season.

Knowing the alternative host plants of cotton flea beetle, its preferences among hosts and host sequence before and after colonization of cotton crop will help in the management of selected certain favourable hosts to mitigate their role in the build-up of this pest population. Especially the late season host plant species contribute a lot in supporting the adult cotton flea beetle through the harsh period i.e., until it aestivates/ diapauses or move to perennial trees that may be serving as host plants. Hence, better and timely management of alternative host plants is essential for the sustainable cotton crop cultivation through reducing this insect pest population development.

\section{Acknowledgements}

The authors thank the Ethiopian Ministry of Education for providing financial support to this work. The authors also acknowledge the support provided by Gondar Agricultural Research Centre and Werer Agricultural Research Centre.

\section{References}

Abdin, A., 1962. Seed dressing trials. Ann. Report, Gezira Agri. Res. Station.

Abebe, E.A., 2015. Cotton Flea Beetle, Podagrica puncticollis Weise (Coleoptera: Halticidae) in Metema District, Northern Ethiopia: Yield Loss Assessment and Management. Open Access Library Journal, 2: e1128. 
Adewole, M.M., 2010. Host preference in family Malvaceae by Podagrica spp. (Coleoptera: Chrysomelidae): An oligophagus herbivore. Department of crop protection, college of plant science and crop production University of agriculture, Abeokuta, Ogun State, Nigeria.

Adeyela, I.O. and Thomas, I.O., 2013. Effect of mixed cropping and plant extracts on the growth, yield and pest control of jute (Corchorus olitorius L.). Folia Hort., 25: 49-60.

Anonymous, 2011. Canola watch-Estimating flea beetle damage in canola. Canola council of Canada.

Bernays, E.A., 1995. Effects of experience of host-plant selection. In: R.T. Carde and W.J. Bell [eds.], Chemical Ecology of Insects 2. Chapman and Hall, New York, pp. 47-65.

Bukenya, Z.R., 2004. Hibiscus cannabinus L. In: Grubben, G.J.H. \& Denton, O.A. (Editors). PROTA 2: Vegetables/Légumes. PROTA, Wageningen, Netherlands.

Capinera, J.L., 2002. North American vegetable pests: the pattern of invasion. Am. Entomol., 48: 20-39.

Cmoluch, Z., 1988. Remarks on the bionomics of Podagrica fuscicornis (Linnaeus, 1766) (Col., Chrysomelidae). OchronaRoslin, 32: 15-16.

Delahaut, K.A., 2001. Integrated pest management program of the University of WisconsinMadison, USA. Published 201 Hiram Smith Hall. pp. 262.

Dodge, K.L., Price, P.W., Kettunen, J. and Tahvanainen, J., 1990. Preference and performance of the leaf beetle Disonycha pluriligata (Col. Chrysomelidae) in Arizona and comparisons with beetles in Finland. Environ. Entomol., 19: 905-910.

Ermias, S., Geremew, T. and Zeray, M., 2009. Review of Research on Insect Pests of Fiber Crops in Ethiopia. In: the Proceeding of Increasing Crop Production through Improved Plant Protection Volume II, Plant Protection Society of Ethiopia (PPSE). Ethiopian Institute of Agricultural Research (EIAR), Addis Ababa, Ethiopia.

Esayas, T., Abraham G.H. and Mashila, D., 2012. Quantitative and Qualitative Determination of Weeds in Cotton-Growing Areas of Humera and Metema, Northwestern Ethiopia. Ethiop. J. Appl. Sci. Technol., 3: 57-69.

Frohlich, G. and Rodewald, W., 1969. Pests and diseases of tropical crops and their control. Edition Lepzing, Printed in German Democratic Republic, pp. 70.

Furth, D.G., 1979. Zoogeography and host plant ecology of the Alticinae of Israel, especially Phyllotreta; with descriptions of three new species (Coleoptera: Chrysomelidae). Israel Journal of Zoology, 28: 1-37.

Gentry, W., 1965. Crop insects of Northeast Africa-Southeast Asia. ARS, Agricultural Handbook No 273. USDA, Washington, DC, pp. 33.

Haile, A., Tamrat, B. and Gemedo, D., 2012. Floristic diversity, regeneration status, and vegetation structure of woodlands in Metema Area, Amhara National Regional State, Northwestern Ethiopia. Journal of Forestry Research, 23: 391- 398.

Hartmann, T., 1996. Diversity and variability of plant secondary metabolism, a mechanistic view. Entomol. Exp. Appl., 80: 177-188.

Hill, D.S., 1987. Agricultural insect pests of the tropics and their control. Cambridge University Press, Cambridge, London, 46 pp.

Hill, D.S., 1994. Agricultural entomology. Timber Press, Portland, Oregon, Hong Kong, pp. 252-310.

IAR (Institute of Agricultural Research). 1972. Progress report for the period April 1971 to March 1972. Addis Ababa, Ethiopia, pp. 75.

Jones, R.W., Cate, J.R., Martinez, E.M. and Navarro, R.T., 1992. Hosts and seasonal activity of the boll weevil in tropical and subtropical habitats of northeast Mexico. J. Econ Entomol., 85: 74-82. 
Kennedy, J.S., 1978. The concepts of olfactory arrestment and attraction. Physiol. entomol., 3: 91-98.

Kenneth, A.S., 1995. Flea beetle on vegetables. Department of Entomology, NCSU, USA, pp. 34.

La Croix, E.A.S., 1961. Observations on the ecology of the cotton flea beetles in the Sudan Gezira and the effect of sowing date on the level of population in cotton. Bulletin of Entomological Research. 52: 773-83.

Lloyd, G. and Ripper, W.E., 1965. Cotton pests of the Sudan: Their habits and control. Blackwell scientific publications, Oxford, England, pp. 150-153.

Mayoori, K. and Mikunthan, G., 2009. Damage pattern of cabbage flea beetle Phyllotreta cruciferae (Goeze) (Coleoptera: Chrysomelidae), and its associated hosts of crops and weeds. American-Eurasian Journal of Agriculture and Environmental Sciences, 6: 303-307.

Metcalf, R.L., 1993. Destructive and useful insects, 5th edition. McGraw-Hill Book Co., New York, NY, pp. 146-149.

Natural Database for Africa (NDA), 2011.Version 2.0. Addis Ababa University, Ethiopia.

Pollard, D.G., 1955. The identity of the cotton flea beetles of the Sudan. Ann. Mag. Nat.

Pulschen, L., 1990. Compositional, synecology and sociological structure of the agrestal flora in Shewa province, Ethiopia. Angew. Botanik., 64: 445-456.

Ripper, W.E. and George, L., 1965. Cotton Pests of the Sudan. Their habits and control. Blackwell Scientific Publications, Oxford.

Schaffner, U.R.S., 2001. Host Range Testing of Insects for Biological Weed Control: How Can It Be Better Interpreted? BioScience, 51: 951-959.

Schmutterer, H., 1969. Pests of crops in Northeast and Central Africa with particular reference to the Sudan. Gustav. Fischerverlag. Stuttgart. Portland. U.S.A.

Schoonhooven, L.M., Jermy, T. and van Loon, J.J.A., 1998. Host-plant selection: Why insects do not behave normally, pp. 195-220.

Schultz, J.C., 1988. Many factors influence the evolution of herbivore diets, but plant chemistry is central. Ecology, 69: 896-897.

Singer, M.C., Vasco, D., Parmesan, C., Thomas, C.D. and NG, D., 1992. Distinguishing between 'preference' and 'motivation' in food choice: an example from insect oviposition. Anim. Behav., 44: 463-471.

Soroka, J.J., 2008. Flea beetle (Coleoptera: Chrysomelidae: Alticinae). In: Capinera J.L. (Eds.) Encyclopaedia of Entomology Spring, Dordrecht.

Starr, C.K., Severson, R.F. and Kays, S.J., 1991. Volatile chemicals from sweet potato and other Ipomoea: Effects on the behaviour of Cylas formicarius. In: R.K. Jansson and KV. Raman (eds.) Sweet Potato Pest Management: A Global Perspective. West View Press Inc. Boulder, CO.

Taye, T. and Yohannes, L., 1998. Qualitative and quantitative determination of weeds in teff in west-Shewa Zone. Arem, 4: 46-60.

Throne, S., 2007. Flea beetle management for canola, rapeseed, and mustard in the Northern Great Plains. Saskatchewan Agriculture Green Plan Agreement, Canada, pp. 45.

White, T.C.R., 1973. The establishment spread and host range of Paropsis Charybdis Stal (Chrysomelidae) in New Zealand. Pacific Insects, 13: 59-66.

ZongZhao, Z. and SiQin, G., 2005. Feeding habits and host plant differentiation of flea beetles. Acta Entomologica Sinica, 48: 407-417. 